\title{
DETERMINAN KOMPETENSI TERHADAP KINERJA PEGAWAI KANTOR PELAYANAN PAJAK WILAYAH TANGERANG
}

\author{
Widayat \\ Universitas Pamulang, Banten \\ ichamavy@gmail.com
}

Submitted: $19^{\text {th }}$ Sept 2019/ Edited: $23^{\text {rd }}$ November 2019/ Issued: $01^{\text {st }}$ January 2020

Cited on: Widayat. (2020). DETERMINAN KOMPETENSI TERHADAP KINERJA PEGAWAI KANTOR PELAYANAN PAJAK WILAYAH TANGERANG. SCIENTIFIC JOURNAL OF REFLECTION: Economic, Accounting, Management and Business, 3(1), 111-120.

DOI: $10.37481 /$ sjr.v3i1.121

https://doi.org/10.37481/sjr.v3i1.121

\begin{abstract}
Employees must have high performance, why? because serving the community must be with heart, how to be careful, and wholeheartedly. People don't see shabby or grand buildings, they just want to be civilized. Performance of services in the tax office must be a priority, because of that capital awareness of the public to pay taxes. This study wanted to explore information about the performance of tax service employees in the Tangerang region. How is the role of individuals and organizations in creating services. Quantitative research is seen as more effective in terms of time. Therefore, regression analysis was chosen to analyze the data. Data obtained through a questionnaire. The findings show evidence, ability is a major factor in tax service. Knowledge, expertise and experience about taxes is a preference in service. Of course this is inseparable from many factors, among them Educational background, training, and experience.
\end{abstract}

Keywords: Training \& Education, Experience, Competence, Preference

\section{PENDAHULUAN}

Reformasi birokrasi telah menjadi domain utama di lingkungan pemerintahan, baik pusat maupun daerah, baik kementerian maupun non kementerian semuanya berlomba-lomba menyelenggarakan tata kelola yang bersih, transparan, akuntabel, dan profesional demi terselenggaranya pelayanan publik yang modern dan humanis, tidak terkecuali di lingkungan kantor pelayanan pajak wilayah Tangerang. KPP Tangerang berkomitmen untuk menghadirkan pelayanan fiskus yang berkualitas. Menghadirkan pegawai-pegawai yang handal dalam pendampingan dan konsultan pajak bagi masyarakat Tangerang, baik wajib pajak bada/ korporasi atau wajib pajak individu. 
Tentu, konsep tersebut menghadirkan konsekuensi nyata, yakni berupa pembuktian para pegawai yang handal dan profesional.

Untuk mewujudkan hal tersebut, faktor kompetensi di bidang perpajakan adalah prinsip/ fundamental. Asas pelayanan perpajakan adalah pengetahuan dan keahlian tentang pajak, jika pegawai KPP Tangerang tidak mengetahui apa-apa tentang perpajakan maka akan sulit menghadirkan pelayanan yang prima. Selain pegawai harus ramah, pegawai juga wajib ahli di bidang perpajakan, dengan demikian masyarakat umum yang awam pajak sangat terbantu. Mispa, S. (2018), Ratnawati, dkk (2015), dan Felisberto, M. (2019) mengemukakan, kepuasan terbesar masyarakat pada saat datang ke kantor pelayanan pajak adalah para pegawai pajak memudahkan jalannya pengurusan, membantu penyelesaian dan pengisian, dan keramahan pegawai. Hal yang tidak bisa dilupakan jasa mereka, namun masyarakat menghargai atas segala upaya dan kebaikan para pegawai yang telah menghemat waktu masyarakat, membantu ketidaktahuan, dan melayani dengan kesabaran. Rembet, dkk (2018), tanggapan masyarakat tidak lain adalah pelayanan fiskus dari para pegawai yang membantu memudahkan di dalam pengisian dan penyelesaian berkas-berkas yang menyita banyak waktu, dan karena itu semua masyarakat berterimakasih. Vigryana, dkk (2016) menyatakan, kemahiran pegawai pajak tidak hanya di atas penampilan, mereka harus menerapkan pada pembantuan dan pembimbingan wajib pajak di dalam menyelesaikan administrasi pajak.

Selain kompetensi, hal yang menarik untuk dibuktikan sebagai faktor kinerja adalah diklat. Sudah menjadi rutinitas di lingkungan kantor pajak wilayah Tangerang untuk melakukan pelatihan dan pendidikan. Kenapa? Karena pelayanan pajak sangat sarat akan keahlian khusus, di samping kepribadian pegawai harus baik sebagaimana pelayanan bank, di saat yang sama pegawai harus ahli dalam perpajakan, khususnya mengurus administrasi perpajakan bagi masyarakat. Dengan adanya diklat dimaksudkan untuk meningkatkan keterampilan pegawai dalam pelayanan administrasi pajak, selain itu juga menambah kesiapan diri. Dengan adanya pembekalan melalui diklat maka pegawai terbantu di dalam mengetahui hal-hal apa saja yang diperlukan dalam pelayanan perpajakan kepada masyarakat, hal tersebut secara tidak disadari meningkatkan kesiapan diri dan mematangkan mental pelayanan. Marius, dkk (2007), mengemukakan kemampuan menyampaikan dan pelayanan dipengaruhi banyak faktor, 
yang sebelumnya telah dipersiapkan seperti pendidikan dan pelatihan, yang kemudian membentuk kesiapan mental untuk membuktikan keahliannya/ kompetensi.

Punu (2014), tidak dipungkiri seseorang pintar karena belajar. Pengetahuan telah mengantarkan orang siap untuk bekerja, terlebih adanya pelatihan akan memperkuat praktek di lapangan, yakni meminimalisir risiko. Selain itu, diklat adalah sarana pengalaman sebelum terjun langsung untuk bekerja, dengan mempelajari medan terlebih dahulu maka akan mudah menyesuaikan diri, dan tahu apa yang harus dilakukan. Subandi (2016) dan Astra, dkk (2016) menjelaskan, diklat itu tidak wajib diselenggarakan, namun seseorang yang telah mengikuti diklat cenderung menunjukkan perkembangan yang lebih baik, terutama dari sisi pengetahuan dan motivasi kerja. Mereka seakan mendapatkan input baru yang melengkapi sudut pandang lama, dan menjadikan segala sesuatunya lebih baik.

Aristarini, dkk (2014) menambahkan, apa yang telah dilalui lebih membekas termasuk belajar. Pengalaman adalah atribut masa lalu yang telah dilalui, dan menjadi suatu kekuatan di masa mendatang. Sender pengalaman menjadikan seseorang lebih baik dari orang lain, karena ia telah memalui jalan tersebut, sehingga ia tahu hal-hal buruk dan baik apa saja di dalamnya, cara mengatasinya, cara mengerjakan secara efektif, dan lain sebagainya. Pengalaman ibarat protype masa depan, konstruksi masa lalu menciptakan efek luar biasa bagi pikiran dan perilaku, maka tidak heran sebagian besar pegawai profesional menghabiskan dengan belajar dan bekerja pada saat mereka susah, kemudian mereka hadir sebagai SDM unggul di zaman ini. Kapahang, dkk (2014), perusahaan lebih tertarik kepada pegawai yang telah berpengalaman, hal tersebut dipilih karena organisasi tidak perlu mengeluarkan biaya tambahan untuk mengembangkan, namun hanya perlu sedikit memberikan tawaran kompensasi lebih baik, dan itu lebih menguntungkan.

Utami, dkk (2015) kualitas hasil kerja sudah dapat dilihat dari cara pegawai melakukannya, dan pegawai berpengalaman menunjukkan hasil yang berbeda. Mereka mampu memangkas waktu dan biaya, mereka lebih cepat dan lebih baik kualitasnya, maka tingkatan umpan balik keduanya dibedakan. Pegawai yang telah lama mereka tidak hanya tahu cara bekerja, tapi mereka paham kondisinya, sehingga memberikan pelayanan akan mempertimbangkan kebaikan bersama, termasuk eksistensi perusahaan di masa mendatang. 
Vol. 3, No. 1, January 2020

\section{LANDASAN TEORI}

Kinerja harga mati, begitu perusahaan atau organisasi mengatakan. Sesungguhnya kalimat tersebut bukan lelucon namun harapan kemajuan. Ada sindiran halus bagi setiap pegawai, bahwa mereka bekerja untuk berkinerja, namun perusahaan/ organisasi tidak menampikan, banyak faktor yang mengganggu kinerja rendah. Misalnya karakteristik lingkungan, karakteristik pimpinan, karakteristik struktur organisasi, karakteristik pelanggan, dan lain sebagainya yang mungkin tidak sehati dengan karakteristik pegawai itu sendiri. Combs (2006), berkata berkinerja itu mudah, seperti mematikan kompor otomatis, ditekan tombol mati. Namun ketika terjadi kebakaran, siapa yang mampu memadamkannya?, dibutuhkan sumber daya besar dan melibatkan banyak manusia untuk menghentikannya. Kinerja sulit diwujudkan jika pegawai sendiri yang mengendalikannya, terlalu naif organisasi menuntut ini dan itu tanpa berbuat sesuatu. Pegawai membutuhkan dukungan untuk meyakinkan diri bahwa mereka harus berkinerja (Gilboa, et al., 2008; Whitman, et al., 2010; Brown, et al., 2011).

Khan \& Ramachandran (2012) mengatakan, kinerja butuh keahlian, keterampilan, dan pengetahuan. Omong kosong pada kebaikan jika tidak bisa menciptakan produk yang bermanfaat, omong kosong pada sikap dan perilaku sesuai aturan jika tidak menciptakan efisiensi. Kinerja dimaksudkan mencapai tujuan, dan kompetensi syarat utamanya. Tentu semua orang menghendaki maju dan beradab, bukan kumuh tapi pintar, atau kaya tapi arogan. Kinerja tercipta dari keseimbangan sikap dan perilaku yang terdidik, yaitu kompetensi. Kompetensi merupakan perwujudan perilaku yang benar dari akumulasi pengetahuan dan pengalaman. Keduanya terekstraksi ke dalam capaian kerja (Bortoli, et al., 2011). Omorede, et al (2013), kemunduran terjadi karena pegawai tidak terukur cara bekerja, tidak ada syarat keahlian, dan itu banyak menimpa perusahaan-perusahaan di wilayah Afrika gagal.

Diklat adalah salah satu faktor yang mempengaruhi matangnya keahlian dan berdampak pada kinerja. Tidak ada yang mengatakan bahwa saya pintar tanpa belajar, saya ahli mengelas tanpa pelatihan di bengkel, saya bisa merakit komputer tanpa melihat, dll. Semua orang mengatakan berpendidikanlah maka anda berpengetahuan, berlatihlah maka anda terbiasa, keduanya menjadi sebab kompetensi lahir. Yakni perilaku ahli dalam satu kegiatan. Purnomo, dkk (2016), organisasi memahami diklat sebagai upaya yang harus dilakukan dengan tujuan meningkatkan keahlian. Selain itu, 
ada harapan yang hendak dicapai, kemampuan menyesuaikan diri dengan lingkungan baru atau pekerjaan baru. Diklat dimaksudkan meningkatkan kompetensi kerja dan perilaku. Dasar pemikiran tersebut sejalan dengan pernyataan Prasetyo \& Relawan (2017), bekerja itu melibatkan aspek organisasi dan sosial. Maka pegawai yang berkinerja adalah mereka yang membuktikan diri dengan karya dan menjalin hubungan harmonis dengan semua pihak. Diklat adalah salah satu faktor yang dimungkinkan melahirkan perilaku terebut. Edy \& Risambessy (2018) dan Ekaningsih (2013) menambahkan diklat punya kontribusi di dalam meningkatkan kinerja.

Hal lain yang juga berpengaruh adalah pengalaman. Mungkin sedikit sulit menjelaskan bagaimana pengalaman berpengaruh terhadap kompetensi dan kinerja. Namun kita lihat, tetangga atau teman di sekitaran rumah yang telah bekerja pada suatu perusahaan, dengan lamanya bekerja mereka menunjukkan suatu kepintaran di bidangnya. Mereka tahu seluk beluk dan karakteristik tentang tugas yang diembannya, dan mereka menyadari pengalaman telah menempa pribadi yang memahami tugas dengan karakteristiknya.

\section{METODE PENELITIAN}

Membuktikan hipotesis di atas diperlukan satu metode, dan penelitian ini memilih kuantitatif. Penelitian berangkat dari konsep umum untuk melihat sejauh mana fenomena di suatu objek penelitian. Dengan menggunakan instrumen kuesioner, maka penelitian ini optimis dapat menguak informasi yang berguna bagi khasanah keilmuan, khususnya kemajuan KPP pajak wilayah Tangerang.

\section{Tabel 1. Populasi dan Sampel}

\begin{tabular}{clcc}
\hline No & \multicolumn{1}{c}{ Unit Kerja } & Populasi & Sampel \\
\hline 1 & KPP Madya Tangerang & 116 & 31 \\
2 & KPP Pratama Tangerang Timur & 88 & 23 \\
3 & KPP Pratama Kosambi & 81 & 21 \\
\hline & Jumlah & 285 & 75 \\
\hline
\end{tabular}

Sumber: Data penelitian, 2018

Analisis jalur dipilih sebagai cara untuk menganalisis, apakah kompetensi dapat menjadi faktor intervening yan baik bagi ke dua variabel bebas (diklat dan pengalaman), dengan demikian terjadi peningkatan yang signifikan terhadap kinerja. Teknik di dalam menentukan jumlah sampel menggunakan rumus Taro Yamane secara proporsional pada setiap objek penelitian. 
Vol. 3, No. 1, January 2020

\section{HASIL PENELITIAN}

Tabel 2. Hasil Penelitian

\begin{tabular}{|c|lc|c|c|}
\hline No & \multicolumn{2}{|c|}{ Variabel } & Koefisien & Kesimpulan \\
\hline 1 & Diklat & > Kompetensi & 0.296 & Signifikan \\
2 & Pengalaman & > Kompetensi & 0.470 & Signifikan \\
3 & Diklat & > Kinerja & 0.147 & Signifikan \\
4 & Pengalaman > Kinerja & 0.298 & Signifikan \\
5 & Kompetensi $>$ Kinerja & 0.584 & Signifikan \\
\hline
\end{tabular}

Sumber: Data penelitian, 2018

Temuan ini menunjukkan bahwa diklat yang diukur oleh kompetensi memiliki pengaruh terhadap kompetensi pegawai dan besarnya pengaruh secara langsung terhadap kompetensi sebesar 0,296. dapat disimpulkan adanya pengaruh yang positif dan signifikan antara diklat dan kompetensi. Hal ini berarti bahwa semakin banyak diklat yang diikuti akan semakin meningkatkan kompetensi pegawai. Diklat yang dilaksanakan bertujuan untuk meningkatkan kemampuan sumber daya pegawai agar mampu melaksanakan setiap tugas dan pekerjaan sebaik mungkin sehingga memberikan kontribusi terhadap peningkatan kinerja pegawai. Diklat bagi pegawai sangat penting untuk diterapkan karena dengan adanya diklat diharapkan pegawai akan dapat bekerja secara lebih efektif dan efisien terutama untuk menghadapi perubahan-perubahan yang terjadi seperti perubahan teknologi, sosial ekonomi, perubahan metode kerja, menuntut pula perubahan sikap, tingkah laku, keterampilan dan pengetahuan. Berkenaan dengan hal tersebut, segala sesuatu yang menunjang dan mencakup diklat merupakan sesuatu hal yang penting. Adapun materi yang digunakan dalam pelatihan pun harus sesuai dengan kebutuhan pelatihan agar mencapai sasaran. Bahan atau materi yang disajikan dalam pelatihan disiapkan secara tertulis agar mudah dipelajari.

Disamping itu, diklat memiliki hubungan terhadap kinerja melalui pengaruh tidak langsung yang dimediasi oleh kompetensi yang digunakan formula sebagai berikut : $\mathrm{X}_{2}$ ke $Y_{1}->Y_{1}$ ke $Y_{2}=0,296 X 0,584=0,173$. Sehingga, disimpulkan bahwa diklat memiliki pengaruh secara tidak langsung terhadap kinerja pegawai sebesar 0,173. Dan diklat memiliki pengaruh secara langsung terhadap kinerja sebesar 0,147. Selanjutnya dapat disimpulkan bahwa pengalaman kerja memiliki pengaruh secara tidak langsung terhadap kinerja pegawai melalui kompetensi sebesar 0,274, dan pengaruh secara langsung pengalaman kerja terhadap kinerja sebesar 0,298. 
Berdasarkan hasil perhitungan melalui bantuan SPSS diperoleh nilai koefisien jalur sebesar 0,470 dan nilai koefisien korelasi diperoleh sebesar 0,527 dengan nilai probabilitas sebesar $0,000<0,05$. Berarti terdapat pengaruh pengalaman kerja terhadap kompetensi. Pengalaman kerja sebagai pengetahuan atau keterampilan yang telah diketahui atau dikuasai seseorang yang akibat dari perbuatan atau pekerjaan yang telah dilakukan selama beberapa waktu tertentu yang akan berpengaruh terhadap kompetensi seseorang. Selain itu, Pengalaman kerja sebagai proses pembentukan pengetahuan atau keterampilan tentang metode suatu pekerjaan yang berkontribusi terhadap kompetensi seseorang.

Berdasarkan hasil perhitungan melalui bantuan SPSS diperoleh nilai koefisien jalur sebesar 0,147 dan nilai koefisien korelasi diperoleh sebesar 0,430 dengan nilai probabilitas sebesar $0,035<0,05$. Temuan ini menunjukkan bahwa diklat berpengaruh terhadap kinerja pegawai dan besarnya pengaruh secara langsung diklat terhadap kinerja sebesar 0,147. pada prinsipnya pemberian diklat dititikberatkan kepada peningkatan kinerja karena sasaran diklat adalah membantu karyawan untuk melakukan suatu pekerjaan sehingga kinerjanya meningkat.

Berdasarkan hasil penelitian didapatkan data bahwa pengaruh langsung pengalaman kerja terhadap kinerja sebesar 0,298, pengaruh tidak langsung pengalaman kerja terhadap kinerja melalui kompetensi sebesar 0,274 , hal ini lebih besar jika dibandingkan pengaruh langsung diklat terhadap kinerja sebesar 0,147 dan pengaruh langsung diklat terhadap kinerja melalui kompetensi sebesar 0,173. Hal ini berarti bahwa diklat dan pengalaman kerja sama-sama berpengaruh secara signifikan terhadap kinerja, namun demikian karena secara angka lebih besar pengaruh pengalaman kerja terhadap kinerja, dibandingkan pengaruh diklat terhadap kinerja, kiranya hal ini dapat menjadi masukan bagi pimpinan yang berwenang akan perlunya melakukan evaluasi kembali terhadap program diklat yang telah dibuat agar lebih fokus terhadap diklat yang memang benar-benar dibutuhkan oleh pegawai guna mendukung aktivitas kerja seharihari dalam rangka mencapai tujuan organisasi. Sehingga kedepan diharapkan pengaruh langsung maupun tidak langsung antara diklat terhadap kinerja makin meningkat.

Berdasarkan hasil perhitungan melalui bantuan SPSS diperoleh nilai koefisien jalur sebesar 0,584 dan nilai koefisien korelasi sebesar 0,798 dengan nilai probabilitas sebesar $0,000<0,05$, berarti terdapat pengaruh kompetensi terhadap kinerja pegawai. 
Hal ini menunjukkan bahwa kompetensi berpengaruh terhadap kinerja pegawai dan besarnya pengaruh secara langsung kompetensi terhadap kinerja sebesar 0,584.

\section{KESIMPULAN}

Pengaruh diklat dan pengalaman baik secara langsung maupun tidak langsung terhadap kinerja adalah signifikan. Dengan demikian, diklat dan pengalaman merupakan faktor yang diperlukan di dalam organisasi. Terlepas pimpinan memberlakukan kebijakan lain, bahwa pegawai harus tetapi dikembangkan melalui program pelatihan. Pegawai harus diberikan kesempatan untuk melakukan banyak hal dan di berbagai divisi sehingga meningkat pengalaman kerja. Dengan demikian yang menjadi kunci kinerja pegawai yaitu kompetensi meningkat.

Tidak dapat dipungkiri, temuan ini menunjukkan bahwa kompetensi tidak hadir dengan sendirinya. Kompetensi hadir karena dua dimensi penting, yakni pendidikan, pelatihan dan pengalaman. Seorang pegawai dikatakan mampu atau ahli bekerja karena telah melalui ketiga tahapan tersebut. Pegawai butuh kecerdasan berpikir dalam mencapai kinerja, pegawai dapat siap bekerja jika telah mendapatkan pelatihan tentang cara-cara menjalankan tugas, dan pegawai dapat menyelesaikan lebih baik jika telah mendapatkan pengalaman.

\section{DAFTAR PUSTAKA}

Aristarini, L., Kirya, I. K., Yulianthini, N. N., \& SE, M. (2014). Pengaruh Pengalaman Kerja, Kompetensi Sosial dan Motivasi Kerja terhadap Kinerja Karyawan pada Bagian Pemasaran PT Adira Finance Singaraja. Jurnal Jurusan Manajemen, 2(1).

ASTRA, F., Mandey, J., \& Londa, V. (2016). Pengaruh Pendidikan dan Pelatihan Struktural terhadap Kompetensi Kepemimpinan Aparatur Sipil Negara Studi di Sekretariat Daerah Kota Bitung. Jurnal Administrasi Publik, 3(400).

Bortoli, L., Bertollo, M., Comani, S., \& Robazza, C. (2011). Competence, achievement goals, motivational climate, and pleasant psychobiosocial states in youth sport. Journal of Sports Sciences, 29(2), 171-180.

Brown, S. D., Lent, R. W., Telander, K., \& Tramayne, S. (2011). Social cognitive career theory, conscientiousness, and work performance: A meta-analytic path analysis. Journal of Vocational Behavior, 79(1), 81-90.

Combs, J., Liu, Y., Hall, A., \& Ketchen, D. (2006). How much do high-performance work practices matter? A meta-analysis of their effects on organizational performance. Personnel psychology, 59(3), 501-528. 
Edy, L., \& Risambessy, A. (2018). PENGARUH DIKLAT, DISIPLIN KERJA DAN KOMPETENSI TERHADAP KINERJA PEGAWAI BALAI DIKLAT KEAGAMAAN AMBON. Jurnal Soso-Q, 6(1), 18-26.

Ekaningsih, A. S. (2013). Peran Pendidikan dan Pelatihan Serta Kompetensi dalam Upaya Peningkatan Kualitas Sumber Daya Aparatur (Studi pada Dinas Perhubungan Kota Tarakan). Jurnal Borneo Administrator, 9(2).

Felisberto, M. (2019). Pengaruh Kompetensi Fiskus Dan Pelaksanaan E-Filling Terhadap Kepuasan Wajib Pajak (Survei Pada Pegawai Pajak Kpp Pratama Surabaya Sukomanunggal. Jurnal Mitra Manajemen, 3(10), 1006-1021.

Gilboa, S., Shirom, A., Fried, Y., \& Cooper, C. (2008). A meta-analysis of work demand stressors and job performance: examining main and moderating effects. Personnel Psychology, 61(2), 227-271.

Kapahang, J. O., Kojo, C., \& Uhing, Y. (2014). Pendidikan, Pengalaman Kerja Dan Kompetensi Pengaruhnya Terhadap Kinerja Karyawan Pada PT. PLN (Persero) Wilayah Suluttenggo. Jurnal EMBA: Jurnal Riset Ekonomi, Manajemen, Bisnis dan Akuntansi, 2(4).

Khan, K., \& Ramachandran, S. (2012). Conceptual framework for performance assessment: competency, competence and performance in the context of assessments in healthcare-deciphering the terminology. Medical teacher, 34(11), 920-928.

Marius, J. A., Sumardjo, S., Slamet, M., \& Asngari, P. S. (2007). Pengaruh faktor internal dan eksternal penyuluh terhadap kompetensi penyuluh di Nusa Tenggara Timur. Jurnal penyuluhan, 3(2).

Mispa, S. (2018). Pengaruh Kualitas Pelayanan dan Kompetensi Fiskus Terhadap Kepuasan Wajib Pajak. Tangible Journal, 3(2), 155-168.

Omorede, A., Thorgren, S., \& Wincent, J. (2013). Obsessive passion, competence, and performance in a project management context. International Journal of Project Management, 31(6), 877-888.

Prasetyo, A. I., \& Relawan, I. N. (2017). Analisis Pengaruh Pendidikan Dan Pelatihan Terhadap Kinerja Melalui Kompetensi (Studi Pada Unit SDM PT Kereta Api Indonesia (Persero) Bandung). Jurnal Ecodemica: Jurnal Ekonomi, Manajemen, Dan Bisnis, 1(1), 107-117.

Punu, A. S. (2014). Pengaruh Pendidikan dan Pelatihan (Diklat) Terhadap Kompetensi Kerja Aparatur di Sekretariat Daerah Kota Tomohon. Jurnal Administrasi Publik, 3(004).

Purnomo, D., Sudana, I. P., \& Mananda, I. G. S. (2016). PENGARUH PENDIDIKAN DAN PELATIHAN TERHADAP KOMPETENSI SERTA DAMPAKNYA PADA KINERJA PRAMUWISATA BALI. Jurnal IPTA, 4(2), 51-57.

Ratnawati, V., Ramadhani, F., \& Rusli, R. (2015). Pengaruh Kualitas Pelayanan, Akses, Dan Kompetensi Fiskus Terhadap Kepuasan Pemenuhan Kewajiban Perpajakan 
Wajib Pajak Badan. Jurnal Online Mahasiswa Fakultas Ekonomi Universitas Riau, 2(2).

Rembet, A., Karamoy, H., \& Elim, I. (2018). Pengaruh Modernisasi Sistem Administrasi Perpajakan Dan Kompetensi Pegawai Pajak Terhadap Kepuasan Wajib Pajak. Jurnal Riset Akuntansi Going Concern, 13(04).

Subandi, M. (2016). Pengaruh Pendidikan dan Pelatihan (Diklat) Terhadap Kompetensi Pegawai Dinas Perhubungan Kabupaten Kutai Kartanegara. Jurnal ilmu sosial MAHAKAM, 5(1), 21-36.

Utami, U. I., Kamaliah, K., \& Rofika, R. (2015). Pengaruh Integritas, Obyektivitas, Kerahasiaan, Kompetensi, Dan Pengalaman Kerja Terhadap Kinerja Auditor Pada Inspektorat Provinsi Riau. Jurnal Online Mahasiswa Fakultas Ekonomi Universitas Riau, 2(2).

Vigryana, E. E., Mukzam, M. D., \& Ruhana, I. (2016). Pengaruh Kompetensi Fiskus dan Kualitas Pelayanan terhadap Kepuasan Wajib Pajak (Studi pada Wajib Pajak yang Terdaftar di Kantor Pelayanan Pajak Pratama Malang Utara). Jurnal Mahasiswa Perpajakan, 9(1).

Whitman, D. S., Van Rooy, D. L., \& Viswesvaran, C. (2010). Satisfaction, citizenship behaviors, and performance in work units: A meta-analysis of collective construct relations. Personnel psychology, 63(1), 41-81. 